\title{
A cultura material das práticas de beberagem quilombola e suas contribuições para a cerâmica afro-indígena
}

\section{The material culture of quilombola drinking practices and their contributions to Afro-Indigenous pottery}

Mayre Dione Mendes da Silva Mascarenhas ${ }^{1}$

Este estudo se propõe a compreender as interações entre a materialidade do artesanato, particularmente canecas, jarros e potes, e os sentidos atribuídos ao ato de preparar, consumir e servir a bebida Emu no cotidiano de comunidades quilombolas. Tais interações evidenciam experiências compartilhadas, no sentido de preservar modos de vida ancestral, bem como a cultura local, configurando-se como prática educativa, na qual saberes relacionados às técnicas da cerâmica são produzidos e transmitidos entre os membros das comunidades. Focaliza-se na pesquisa a bebida sagrada Emu, de origem africana com interseção com a cultura indígena, produzida nas comunidades quilombolas de África e Laranjituba, localizadas na cidade de Abaetetuba, Pará. A produção do Emu é uma tradição de aproximadamente 300 anos, feita a partir da mistura das ervas coletadas na mata. A bebida passa por um ritual de consagração, considerado por eles sagrado, e, somente após esse processo, estará pronta para ser utilizada em rituais de cura e também em festividades. A cultura material que perpassa as práticas de beberagem evoca questionamentos que impulsionaram esta pesquisa, a saber: como a fabricação do Emu impulsionou os saberes relacionadas à produção da cerâmica? Como a cerâmica utilitária é compreendida como patrimônio material quilombola? O percurso metodológico escolhido segue o estudo etnográfico e arqueológico, sendo os artefatos as pistas a serem seguidas do modo de beber de povos da diáspora africana em interseção com os indígenas. Tanto a tradição de fabricar e consumir o Emu quanto a tradição de fazer a cerâmica contribuem para a geração de renda e também para a coesão social da comunidade ao fortalecer os vínculos culturais e identitários, assim como apontam o encontro da cultura indígena com a cultura africana na Amazônia. As sociabilidades centradas na produção e no consumo de bebidas fermentadas entre as populações indígenas são conhecidas desde muito tempo; há relatos e documentos da história oficial e registro de consumo da beberagem como uma prática cultural amplamente disseminada entre os indígenas no Brasil colonial, de acordo com Maria Betânia B. Albuquerque. No entanto, ao que se refere às populações quilombolas na Amazônia, ainda há poucos estudos sobre tais práticas, principalmente se pensadas enquanto processos educativos em interface com a Antropologia e com a História Cultural. Este fato aponta a perspectiva de atualização desse campo de pesquisa, no sentido de ampliar os estudos já realizados até aqui sobre beberagens. Ao descrever a cultura material que envolve a fabricação do Emu, esta pesquisa visa contribuir com os estudos no campo da história cultural, apoiada nas teorias de Peter Burke, de Tim Ingold, com educação da atenção, de saberes culturais de Maria Betânia B. Albuquerque, entre outros. 
Palavras-chave: educação; beberagem; cerâmica; quilombolas.

Keywords: education; drinking; pottery; quilombolas.

1 Mestranda em Educação na Universidade do Estado do Pará. 